\title{
PARTICIPAÇÃO DE IDOSOS EM ATIVIDADES DE AVENTURA NA NATUREZA: reflexões sobre aspectos socioambientais
}

\author{
Adriana Aparecida da Fonseca Viscardi' \\ Juliana de Paula Figueiredo \\ Priscila Mari dos Santos Correia ${ }^{3}$ \\ Alcyane Marinho ${ }^{4}$
}

\section{RESUMO}

Este estudo objetivou analisar as percepções de 11 idosos sobre aspectos socioambientais relacionados à prática de atividades de aventura na natureza. Trata-se de uma investigação de campo, descritiva, exploratória, com abordagem qualitativa dos dados. Após uma intervenção prática com duas atividades de aventura na natureza - stand up paddle e trilha - os dados da pesquisa foram obtidos por meio da aplicação de uma entrevista semiestruturada, elaborada especificamente para esta investigação. As informações coletadas foram organizadas no software NVivo, versão 10.0, e analisadas descritivamente, por meio de elementos da técnica de análise de conteúdo. Os resultados apontam que os idosos perceberam o estabelecimento de relações sociais positivas durante a intervenção prática, seja entre os participantes ou com os instrutores. Quanto às reflexões sobre as questões ambientais foram mencionados aspectos amplos, como degradação, conservação, comportamento, sentimentos e ações relacionadas à natureza; e aspectos pontuais, como desmatamento, poluição e falta de água.

Palavras-chave: Idoso. Ambiente. Atividade de lazer

1 Mestranda no Programa de Pós-Graduação da Universidade Federal de Santa Catarina (UFSC). Florianópolis/ Santa Catarina, Brasil. E-mail: adrianaapfonseca@yahoo.com.br

2 Doutoranda do Programa de Pós Graduação da Universidade Federal de Santa Catarina (UFSC). Florianópolis/ Santa Catarina, Brasil. E-mail: julianapfig@hotmail.com

3 Doutoranda do Programa de Pós Graduação da Universidade Federal de Santa Catarina (UFSC). Florianópolis/ Santa Catarina, Brasil. E-mail: priscilamarisantos@hotmail.com

4 Doutora em Educação Física. Professora adjunta do Departamento de Educação Física do Centro de Ciências da Saúde e do Esporte (CEFID) da Universidade do Estado de Santa Catarina (UDESC), Professora Permanente do Programa de Pós-graduação em Educação Física do Centro de Desportos (CDS) da Universidade Federal de Santa Catarina (UFSC). Florianópolis/Santa Catarina, Brasil. E-mail: alcyane.marinho@hotmail.com 


\title{
ELDERLY PARTICIPATION IN ADVENTURE ACTIVITIES IN NATURE: reflections about environmental aspects
}

\begin{abstract}
This paper aims to analyze the perceptions of social and environmental aspects related to the practice of adventure activities in nature of 11 elderly participants. It is a descriptive exploratory field search with qualitative approach. After a practical intervention of two adventure activities in nature - stand up paddle and trail - the survey data were obtained by a semi-structured interview, designed specifically for this research. The information collected were organized in NVivo software, version 10.0, and analyzed descriptively by the technique of content analysis. The results show that the participants have the perception of the establishment of positive social relations during the practice intervention, either between the participants or the instructors. About the environmental issues considerations, the participants mentioned several aspects as degradation, conservation, behavior, feelings and actions related to nature; and punctual aspects, such as deforestation, pollution and water shortage.
\end{abstract}

Key-words: Elderly. Environment. Leisure activities

\section{PARTICIPACIÓN DE ANCIANOS EN LAS ACTIVIDADES DE AVENTURA EN LA NATURALEZA: reflexiones sobre los aspectos socioambientales}

\section{RESUMEN}

Este estudio tuvo como objetivo analizar las percepciones de 11 personas de edad avanzada en los aspectos sociales y ambientales relacionados con la práctica de actividades de aventura en la naturaleza. Es una investigación exploratoria descriptiva con enfoque cualitativo. Después de una intervención práctica con dos actividades de aventura en la naturaleza - stand up paddle y pista - los datos se obtuvieron mediante la aplicación de una entrevista semi-estructurada, diseñada específicamente para esta investigación. La información se organizó en el software NVivo, versión 10.0, y se analizaron a través de la técnica de análisis de contenido. Los resultados muestran que los ancianos se han dado cuenta del establecimiento de relaciones sociales positivas durante la intervención práctica, sea entre participantes o entre instructores. Las reflexiones sobre las cuestiones ambientales tratan aspectos generales de degradación, conservación, comportamiento, sentimientos y acciones relacionadas a la naturaleza; y puntual, como deforestación, contaminación y falta de agua.

Palabras clave: Edad avanzada. Médio ambiente. Actividad de ocio 


\section{INTRODUÇÃO}

A busca pela aventura, o desvendar de novos caminhos e a superação de limites pessoais fazem parte da própria história da humanidade. Desde os tempos mais remotos, o ser humano desafiava-se na exploração de ambientes naturais desconhecidos, motivado por um instinto natural de preservação da sua espécie. Com o passar dos anos e na sociedade contemporânea, o desejo de contato com a natureza tem aumentado expressivamente em diferentes segmentos sociais, assumindo, contudo, novas conotações. A vivência da aventura no meio natural tomou rumos turísticos e, até mesmo, passou a caracterizar o estilo de vida de algumas pessoas, fazendo-se presente nos momentos de lazer (AZEVEDO; COCCHIARALE; COSTA, 2010).

É importante destacar que a aventura constitui-se em um termo dinâmico, que se associa a diferentes palavras para retratar suas práticas, como por exemplo: esportes de aventura (PAIXÃO et al., 2011), práticas corporais de aventura (BRASIL, 2016), atividades físicas de aventura na natureza (BETRÁN; BETRÁN, 2006), dentre outras que evidenciam a complexidade do fenômeno e as opções acadêmicas, políticas e epistemológicas dos estudiosos do assunto. Contudo, neste estudo, adota-se o conceito atribuído ao termo atividades de aventura na natureza (MARINHO, 2008; SANTOS et al., 2015), acreditando-se que ele abarca a multiplicidade de alternativas de vivências no ambiente natural, com atributos inovadores e diferenciados dos esportes tradicionais; e considerando-se as particularidades das situações de prática, dos objetivos, dos recursos e dos equipamentos utilizados para a realização dessas atividades. Nesta perspectiva, as atividades de aventura na natureza são entendidas como possibilidades significativas de vivências no lazer (SANTOS; MARINHO, 2014).

O lazer pode ser definido, segundo Gomes (2014), por meio de uma dimensão cultural, na qual ocorre a articulação de três elementos: o tempo/espaço social, as manifestações culturais, e as ações/atitudes ligadas ao lúdico. Ainda segundo a autora, a interação desses três elementos, por meio da vivência lúdica das manifestações culturais em um espaço/tempo determinado e influenciado pela conjuntura social, podem contribuir para um repensar sobre os limites e as possibilidades da nossa existência, tanto individual, quanto coletivamente. Além da possibilidade de desenvolvimento pessoal e social que o lazer enseja, apontada por Gomes (2014) e também por Marcellino (2012), destaca-se o potencial educativo do lazer, por meio do contato, da percepção e da reflexão sobre o outro e sobre o meio. Nesse contexto educativo, o lazer junto à natureza pode estimular o desenvolvimento de valores.

Considerando esse potencial educativo do lazer no ambiente natural, focaliza-se o conceito da educação ambiental, aqui entendida como educação política, capaz de possibilitar a participação e o engajamento crítico e criativo das pessoas, considerando que ela pode fomentar relações de respeito e de comprometimento com o outro e com o ambiente, a partir de uma atuação local com pensamento global, no sentido de reivindicar justiça social, cidadania e ética nas questões socioambientais (REIGOTA, 2009; SORRENTINO, 2002, 2015). A partir dessa perspectiva, para que a educação ambiental possa ser 
concretizada em ações, é preciso que as distintas populações - crianças, jovens, adultos, idosos - sejam ouvidos e estimulados a falar e a refletir sobre o assunto (SORRENTINO, 2002).

Betrán e Betrán (2006) sugerem que o fenômeno aventura pode se constituir em uma ferramenta pedagógica, visto que, sob a orientação de um profissional capacitado, pode favorecer a conscientização sobre o meio natural e a sensibilização com relação aos problemas ambientais a partir da interação do participante com a natureza. Outros estudos corroboram com esses pressupostos (CHAO et al., 2015; MARINHO, 2008; MARINHO; INÁCIO, 2007), indicando que as características das atividades de aventura na natureza - por serem imbuídas de inúmeros significados, relacionados ao respeito ao ambiente, à natureza, à vida e às relações humanas, e facilitadoras da vivência de emoções, de descobertas, de superação de desafios e de relações interpessoais e com o meio natural podem promover reflexões e mudanças de pensamentos e de comportamentos a favor da conservação ambiental em diferentes fases da vida, inclusive durante a velhice.

Ainda que tais reflexões e atitudes não resultem, necessariamente, em mudanças de caráter dos participantes (BROOKES, 2003), a experimentação de uma forma diferenciada de relação com o ambiente, crítica e criativa, pode oportunizar o exercício da cidadania e possibilitar que os comportamentos pró-ambientais sejam mais frequentes (MARINHO; INÁCIO, 2007), ampliando as possibilidades do lazer, inclusive, a partir das atividades de aventura na natureza.

Frente a esse cenário, pode-se pensar na inserção dos idosos nas atividades de aventura na natureza, pois esses indivíduos vivenciaram um significativo movimento ambiental ocorrido nas décadas de 1960 e 1970, quando o assunto efetivamente passou a integrar as discussões das políticas internacionais. Além disso, por sua experiência de vida, os idosos podem perceber o mundo "com outros olhos", contribuindo para as reflexões e discussões sobre as questões socioambientais (CHAO et al., 2015). Apesar do recente aumento da participação de idosos em atividades de aventura na natureza, ainda são poucos os estudos nacionais que investigam variados aspectos relacionados à inserção dessa população nessas atividades, tais como: motivos de aderência às atividades de aventura na natureza; emoções sentidas antes, durante e após a prática das mesmas; principais dificuldades encontradas durante as práticas; as relações de valores referentes a essas experiências na vida dos idosos; e valores pró-ambientais (CHAO et al., 2015; DIAS, 2006).

Este estudo teve como objetivo analisar as percepções de idosos integrantes de um programa de extensão universitária em Santa Catarina sobre aspectos socioambientais relacionados à prática de atividades de aventura na natureza, mais especificamente a uma vivência de trilha e de stand up paddle. Um aspecto inovador deste estudo está no fato de os participantes não serem praticantes assíduos de atividades de aventura na natureza, assim como nunca terem praticado stand up paddle antes desta pesquisa. Dessa forma, torna-se instigante investigar como esses idosos percebem as questões socioambientais atreladas a tais atividades, podendo fortalecer a literatura acerca do assunto e impulsionar outras pesquisas e intervenções a partir da prática de atividades de aventura na natureza por idosos nos momentos de lazer. 


\section{METODOLOGIA}

Este estudo foi desenvolvido por meio de uma pesquisa de campo, com corte transversal, do tipo descritiva exploratória, com abordagem qualitativa dos dados (GIL, 2008; MINAYO, 2012a); tendo como participantes 11 idosos integrantes de um programa de extensão de uma universidade pública de Santa Catarina. Nesse programa, os idosos participam de atividades educacionais, culturais, artísticas, físicas, fisioterapêuticas e de apoio psicológico, tais como: teatro, dança, ginástica, informática, dentre outras atividades; podendo optar por, no máximo, duas atividades, que ocorrem em horários e locais diferenciados, dentro das instalações universitárias. Dessa forma, não são oferecidas atividades de aventura na natureza como possibilidades de práticas no contexto deste programa de extensão universitária. Os idosos foram selecionados para participarem desta pesquisa mediante o atendimento dos seguintes critérios de inclusão: estarem regularmente matriculados no referido programa; apresentarem avaliação médica atestando a aptidão para a prática das atividades de aventura na natureza; nunca terem praticado stand up paddle; e aceitarem participar voluntariamente da pesquisa por meio da assinatura de um Termo de Consentimento Livre e Esclarecido. Inicialmente, a intenção era de que os idosos não tivessem praticado nem stand up paddle nem trilha; no entanto, durante o convite inicial para participação do estudo, todos mencionaram ter realizado trilha, pelo menos, uma vez na vida, mesmo que durante a infância ou a juventude. Portanto, este critério precisou ser excluído, mantendo-se, apenas, o critério de nunca terem praticado stand up paddle.

A pesquisa foi aprovada pelo Comitê de Ética em Pesquisas Envolvendo Seres Humanos da Universidade do Estado de Santa Catarina por meio do parecer 881.069, de 22 de novembro de 2014. Em março de 2015, durante uma manhã, foi realizada a intervenção prática, por meio da realização de uma trilha, com duração de 40 minutos; e de stand up paddle, com duração de 60 minutos. Ambas as atividades foram realizadas na Lagoa do Peri, localizada na cidade de Florianópolis (SC), Brasil, tratando-se de atividades que não fazem parte das modalidades oferecidas pelo programa de extensão, realizadas, portanto, exclusivamente para essa pesquisa.

Deve-se esclarecer que essas atividades de aventura na natureza foram escolhidas pelo fato de Florianópolis (SC) ser uma cidade litorânea, com lagoas onde a prática de atividades aquáticas é comum e também pelo fato de a cidade apresentar inúmeras trilhas, com diferentes níveis de dificuldade. Sendo assim, selecionou-se a Lagoa do Peri para a realização da intervenção, com o intuito de possibilitar mais segurança aos participantes, pois a trilha escolhida é considerada de nível fácil e a Lagoa em questão apresenta águas calmas, sendo apropriada à prática do stand up paddle para iniciantes.

As atividades práticas foram conduzidas por cinco responsáveis, sendo três Profissionais de Educação Física e dois instrutores especializados em stand up paddle. Estes instruíram e orientaram os participantes quanto às especificidades da trilha e do stand up paddle, bem como quanto à utilização dos equipamentos de segurança. Os Profissionais de Educação Física, por sua vez, acompanharam toda a intervenção e também ministraram uma sessão de 10 minutos de exercícios de alongamento e aquecimento muscular, antes 
da prática, com o objetivo de preparar o corpo para as atividades e minimizar o risco de possíveis lesões; e uma sessão de 10 minutos de exercícios de relaxamento muscular, após a intervenção, com o intuito de diminuir o risco de possíveis dores musculares e de facilitar o retorno do corpo ao estado de repouso. O grupo foi acompanhado por um Técnico em Enfermagem, quem disponibilizou os equipamentos básicos de emergência, caso alguém necessitasse de algum atendimento. Contudo, não ocorreram intercorrências que necessitassem a utilização dos equipamentos de emergência.

$\mathrm{O}$ instrumento de coleta de dados utilizado foi um roteiro de entrevista semiestruturada, elaborado especificamente para este estudo, contendo duas perguntas: Como foi seu relacionamento com os outros praticantes durante as atividades? As atividades despertaram em você algum sentimento em relação ao ambiente? Qual(is)? Também foi utilizado diário de campo para anotações no dia da intervenção prática e da entrevista, sendo esta última aplicada pela pesquisadora principal deste estudo e respondida individuamente pelos idosos nos dois dias subsequentes ao dia em que ocorreu a intervenção prática, em horários previamente agendados.

Por se tratar de uma entrevista semiestruturada, houve a possibilidade de o participante falar sobre o tema em questão, sem se prender às perguntas básicas aplicadas pela pesquisadora principal; característica essencial desse tipo de entrevista, conforme explica Minayo (2012b). Também foram coletadas informações para caracterização dos participantes (tais como: sexo, idade, escolaridade e atividades praticadas no programa de extensão). Para registro das entrevistas foi utilizado um gravador de áudio. Os áudios foram transcritos integralmente pela pesquisadora principal deste estudo.

As informações coletadas foram organizados no software NVivo, versão 10.0, e analisadas por meio de elementos da técnica de análise de conteúdo, seguindo as orientações de Bardin (2009). Para a apresentação dos resultados, quando da reprodução da fala dos idosos, foram utilizados nomes fictícios para representá-los, a fim de preservar suas identidades, seguida da idade real de cada um.

\section{Resultados e discussões}

Quanto às características dos participantes, três são do sexo masculino e oito do sexo feminino com média de idade de $65 \pm$ 4,4 anos. Com relação ao nível de escolaridade, um cursou o ensino fundamental incompleto; dois, ensino fundamental completo; cinco, ensino médio completo; e, três, ensino superior completo, sendo que um destes cursou pós-graduação. As atividades praticadas pelos participantes do estudo no programa de extensão universitária são: dança, natação, canto, hidroginástica, ginástica, pilates e teatro.

No que concerne às percepções sobre os aspectos socioambientais relacionados às atividades de aventura na natureza vivenciadas, foram evidenciados, nas respostas dos idosos, fatores associados às suas histórias de vida, à velhice, ao contexto histórico e ao local da cidade onde residem, repercutindo no fortalecimento e no avanço das discussões sobre o tema. Assim como Marinho e Santos (2014), entende-se que percepções sobre o 
ambiente envolvem as coletividades e as questões sociais, as quais, por sua vez, influenciam e são influenciadas pelas questões ambientais, sendo, portanto, apropriada a utilização do termo "socioambiental". Contudo, considerando que os aspectos sociais e os aspectos ambientais foram respondidos separadamente pelos idosos participantes, ambos os aspectos foram abordados desta forma no presente artigo.

\section{Reflexões dos idosos sobre aspectos sociais}

Marinho (2008) destaca que as atividades de aventura na natureza oportunizam o estabelecimento de diferentes relações entre os envolvidos, sendo capazes de impulsionar a criação de novos laços de amizade, mostrando-se como possibilidades férteis para reflexões relacionadas à vida social contemporânea. Conforme Marinho et al. (2016), as atividades de aventura na natureza podem estimular a autonomia, a autodescoberta, a cooperação, a relação ser humano-natureza, a reflexão e a exploração de sensações e emoções.

No presente estudo, no que se refere às reflexões sobre os aspectos eminentemente sociais vivenciados durante a trilha e o stand up paddle, a maioria dos idosos teve uma percepção positiva, por meio da maior interação coletiva, do estreitamento de laços de amizade e da possibilidade de novas amizades, quando se referiram às interações com os outros participantes, conforme pode ser observado nas seguintes falas: "[...] Sem estresse, todo mundo colaborando, participando, foi bem legal, eu gostei." (MARA, 74); "Foi maravilha, eu fui feliz, e foi bom, apesar de eu ser um pouco tímida, mas me relacionei bem com todo mundo." (EVA, 67).

Segundo Mazo, Lopes e Benedetti (2009), com a chegada da aposentadoria e com o afastamento do trabalho, alguns idosos passam a perceberem-se improdutivos e inúteis na sociedade e acabam por se isolarem nas relações familiares, sentem-se como um fardo, como se a rotina familiar se alterasse por sua culpa; além disso, os estereótipos criados em função de um comportamento esperado dos idosos podem limitar suas vivências. Essa situação pôde ser observada durante a intervenção prática, quando alguns idosos solicitaram que fossem registradas fotos deles realizando stand up paddle, para que pudessem comprovar para suas famílias que realmente são capazes de tal feito.

Na mesma perspectiva, Wheaton (2016) realizou uma pesquisa no Reino Unido envolvendo idosos do sexo masculino e do feminino, os quais praticavam surfe no lazer, de modo a investigar os significados dessa modalidade de aventura na vida e na identidade desses praticantes à medida que envelhecem. O estudo identificou que, ao passso que muitas vezes o processo de envelhecimento é considerado uma fase de declínio cognitivo e físico, para os idosos praticantes de surfe investigados, a modalidade em questão favorece o reconhecimento sobre sua própria identidade, bem como o controle da ansiedade presente no processo do envelhecimento, mostrando, assim, as capacidades físicas, cognitivas e psicológicas desses idosos, independentemente da idade.

Esses são alguns dos motivos que justificam a importância de se preservar a convivência social nessa fase da vida, seja no convívio familiar ou em grupos de sociabilidade. 
Oliveira e Nascimento (2014) afirmam que durante muitos anos e, especialmente no Brasil, evidenciou-se uma desvalorização e não aceitação da velhice; no entanto, recentes pesquisas científicas relacionadas a essa população vêm mudando essa concepção, enfatizando a importância de uma população idosa ativa, independente, autônoma, integrada à sociedade e participativa.

Rizzolli e Surdi (2010), além de encontrarem em seu estudo o aspecto social como motivação para a participação de idosos em grupos de convivência, enfatizam que, por meio das relações sociais, o idoso tem a oportunidade de conhecer pessoas novas, construir laços simbólicos de identificação, fazer novos amigos, compartilhar suas vivências, informações, conhecimentos e reflexões, exercer a cidadania e fugir do isolamento. Gomes (2004) salienta o importante papel do lazer como possibilidade de reinvindicação à participação social, a qual, não raramente, apresenta-se com obstáculos para o envolvimento do público idoso em determinados contextos e atividades específicas, como no âmbito da própria prática do stand up paddle.

Em estudo longitudinal realizado por Gilbertson e Ewert (2015), foram analisados os motivos que levam pessoas de diferentes faixas etárias a realizarem diversas modalidades de atividades de aventura na natureza. Os autores constaram quatro principais motivações: aspectos sociais, fuga da rotina, busca por sensações diversas e melhora da autoimagem.

Contudo, os motivos relacionados às relações sociais e à fuga da rotina tiveram considerável aumento ao longo dos seis anos de desenvolvimento da pesquisa, enquanto que os motivos ligados à melhora da autoimagem diminuíram e os relacionados à busca por sensações mantiveram-se constantes, sugerindo que as interações sociais têm se tornado fundamentais nos momentos de vivência de atividades de aventura na natureza.

Nesse sentido, durante a entrevista os idosos aqui investigados destacaram as relações sociais, enfatizando que as interações vivenciadas com outros participantes estavam entre os aspectos que mais gostaram durante a intervenção: "A reunião, a alegria e estarmos todos juntos, conversando, aquela amizade [...] gostei." (EVA, 67). Alguns idosos refletiram sobre o relacionamento com os instrutores e os Profissionais de Educação Física "Foi muito bom. Pessoal extremamente gentil, a juventude, os instrutores abertos ao diálogo e acompanhando [...]." (CORA, 65) e "A convivência, a gente conheceu outras pessoas, a camaradagem do pessoal, dos professores, a união das pessoas." (ROSA, 56).

No contexto específico das atividades de aventura na natureza, o aspecto social também foi estudado por Dimmock (2009), em pesquisa com mergulhadores, evidenciando a importância de compartilhar as experiências com familiares e da confiança experimentada quando se conhece o companheiro de prática. Tais percepções refletem, além da necessidade de sociabilização, a segurança em saber que não estão sozinhos, por estarem na mesma situação e por saberem que haverá alguém em quem confiar caso ocorra algum imprevisto. Aspectos similares aos constatados no estudo de Dimmock (2009) foram encontrados na pesquisa de Marinho et al. (2016) com 80 estudantes da última fase do curso de Bacharelado em Educação Física de uma universidade pública de Santa Catarina, 
no qual as relações de companheirismo e de confiança nos colegas se destacaram entre as percepções dos estudantes durante vivências de atividades de aventura na natureza, oportunizadas por uma disciplina específica sobre o assunto.

Considerando o discurso de Cora (65), apresentado anteriormente, acrescenta-se a esta discussão a figura dos instrutores de atividades de aventura na natureza, muitas vezes profissionais de lazer com graduação em Educação Física (Marinho et al., 2016). Esses profissionais, de acordo com Tahara e Carnicelli Filho (2009), precisam estar preparados para que as experiências pessoais, sociais e educativas neste âmbito estejam ao alcance de todos (incluindo-se os idosos, em grupos constituídos especificamente por essas pessoas ou em grupos compostos de maneira intergeracional), favorecendo situações que permitam aos participantes desfrutar dos prazeres, das emoções, dos riscos controlados e do processo de integração social que as atividades de aventura na natureza proporcionam.

Dias (2006) menciona que a participação dos idosos em atividades de aventura na natureza pode proporcionar, também, a convivência com pessoas de outras idades, quando for o caso, estabelecendo o relacionamento intergeracional, tal como pôde ser verificado no discurso de Cora (65), participante do presente estudo. A intergeracionalidade pode permitir o estabelecimento de um processo de diálogo, reflexão, solidariedade e cooperação permanente entre gerações nos diferentes espaços sociais (CAMILO, 2014). Percebe-se, com isso, a necessidade de reflexões acerca das relações entre profissionais e idosos participantes, considerando que jovens instrutores precisarão estar preparados para atender a uma geração diferente da sua. Esse aspecto demonstra, mais uma vez, a necessidade de formação profissional adequada para atuar com a população idosa e não apenas a reprodução das atividades de aventura na natureza sem as preocupações específicas para esse público.

Retomando os resultados sobre as relações sociais, uma idosa afirmou não ter ocorrido muita relação interpessoal durante as atividades oportunizadas na intervenção prática deste estudo: "Na verdade a gente não interagiu muito, porque na trilha [...] você vem em fila indiana [...] você não pode conversar muito, e durante a atividade cada um ficou mais preocupado em se manter na atividade do que ficar falando. Mas foi normal." (LIZ, 69). Mesmo quando questionada sobre o momento do lanche coletivo, realizado após a trilha e o stand up paddle, a idosa em questão não mencionou qualquer interação. Contudo, quando indagada sobre a interação com os profissionais que estavam orientando/ auxiliando as atividades, Liz (69) mencionou que a interação foi "boa".

Alguns fatos podem ter influenciado essa situação, como o ocorrido durante a intervenção, em que a participante supracitada ficou mais tempo entretida com a prática de stand up paddle, distanciando-se um pouco dos demais participantes; levando à suposição de que seu interesse estava focado no desempenho durante a prática e não nas interações sociais.

Além disso, essa senhora realiza uma atividade no programa de extensão universitária em horário diferente daqueles realizados pelos demais participantes do estudo, havendo, portanto, menos possibilidades de interações prévias com os demais idosos. Outro 
fato consiste em esta idosa não ter realizado o trajeto com o grupo por residir próximo ao local onde foi realizada a intervenção prática deste estudo; e, também, por estar em contato constante com a natureza, familiarizada com trilhas e atividades em meio natural, conforme ela mesma relatou. Marinho (2008) lembra que as atividades de aventura na natureza estão inseridas em uma dinâmica contraditória que não deve ser negligenciada: se, por um lado, sua vivência, no lazer, geralmente proporciona um significativo sentimento de cooperação e união; por outro, manifesta-se, ainda que não de forma explicitamente imposta, uma cobrança de determinados comportamentos (como não conversar durante a trilha, por exemplo), repercutindo em sentimentos e percepções bastante variados entre os participantes.

As divergências de percepções verificadas no presente estudo também são significativas no sentido de se reafirmar que, nas atividades propostas por um profissional, é importante respeitar a individualidade, as preferências, as características e a história de vida de cada participante, sem desconsiderar as características de cada grupo populacional. Na vivência da cultura corporal, os indivíduos experimentam, transmitem e dividem conceitos, representações e paradigmas particulares, constituídos de sua história, cultura e perspectiva de vida em sociedade e, por isso, únicos (CAMILO, 2014).

No estudo de Chao et al. (2015) sobre o comportamento pró-ambiental de idosos praticantes esporádicos de atividades de aventura e de instrutores dessas atividades foram analisadas as dimensões ecocêntrica, antropocêntrica e de apatia ambiental, sendo que uma não exclui a outra. Os resultados obtidos no referido estudo sugerem que a questão histórica, integrante do constructo vivencial de uma geração, foi determinante para as diferenças de comportamento: os idosos apresentaram maior preocupação com a devastação do ambiente, por terem vivido momentos históricos importantes a favor do movimento ambiental (maior tendência ecocêntrica), quando comparados aos instrutores que não tinham nascido ou não eram adultos nessa época. Estes últimos demonstraram menor tendência de apatia ambiental, ou seja, menor tendência à indiferença e ao não envolvimento com a questão ambiental, além de menor tendência antropocêntrica. Uma das possíveis explicações a essa constatação, apresentada pelos autores do estudo em questão, está relacionada ao fato de os instrutores por eles investigados estarem sentindo as problemáticas ambientais, considerando, especialmente, que precisam do ambiente natural para atuar profissionalmente.

\section{Reflexões dos idosos sobre aspectos ambientais}

Quanto às reflexões em relação ao ambiente natural e aos aspectos ambientais, despertados pela vivência da trilha e do stand up paddle, os idosos falaram sobre impactos ambientais causados pela intervenção humana, como poluição da água, falta de água, desmatamentos, secas, desertificações, enchentes e destruições como em “nós também já temos na parte do oeste de Santa Catarina, problemas de seca e até de desertificação porque foi desmatado" (IVO, 64). Além disso, alguns participantes notaram no local, durante 
a intervenção prática, construções muito próximas da lagoa e lixos deixados no início da trilha: "Fiquei triste de ver muitas coisas ali, pessoas dominando a mata, colocando mangueiras para tirar água do lago para levar para as casas, pessoas querendo construir na beira do lago" (EVA, 67) e "por enquanto ainda está bem preservado, só que já estão botando casa ali" (RUI, 61).

Atitudes que podem ser adotadas para minimizar os impactos ambientais também foram mencionadas pelos idosos, como reflorestamento, além de relatarem algumas ações das quais participam, como limpeza local e das praias e separação do lixo para reciclagem: "nós temos uma associação de moradores há quase trinta anos que faz um trabalho na estradinha. Tinha bastante lixo." (LIZ, 69). Falaram sobre a necessidade de preservação e conservação como: "eu sou adepta a conservar o meio ambiente" (ANA, 62).

Ainda, refletiram sobre o crescente número de pessoas se sensibilizando com relação ao ambiente, sobre as belezas naturais, o privilégio em ter esse ambiente na cidade onde vivem, bem como a importância de conhecer esses locais, de "viver a natureza" para perceber a necessidade de preservá-la:

\footnotetext{
"Isso aí proporciona ao idoso ir ao encontro da mata, ao meio ambiente, vivenciar as coisas, conhecer. Porque tem muita gente que mora aqui e não conhece a ilha, não conhece quase nada da ilha e dos arredores [...] eu acho que a pessoa tem que viver, ir ao encontro da natureza pra ver que ela tem que procurar preservá-la [...]" (IVO, 64).
}

Segundo Marinho e Inácio (2007), há duas formas mais comuns de relacionamento do ser humano com a natureza: percebê-la como meio para suprir suas necessidades por recursos naturais; e por meio do uso temporal, como cenário, local para realização da atividade, como acontece nas atividades de aventura na natureza. Em ambas as formas, a natureza é percebida como provedora e símbolo de consumo. Contudo, essas atividades podem contribuir como uma forma de sensibilização dos indivíduos quanto às questões ambientais.

A variedade de atividades e de contextos físicos, metereológicos e sociais que caracterizam as atividades de aventura na natureza oportunizam diversificadas possibilidades de aproximação das pessoas com a educação ambiental. A ideia de que apenas a transmissão direta de conhecimentos sobre o ambiente, por meio de métodos de ensino tradicionais, são suficientes para a obtenção de uma consciência ambiental e consequente adoção de comportamentos pró-ambientais vem sendo superada pela literatura sobre o assunto (CHAO et al., 2015; MARINHO; INÁCIO, 2007; ROSA; CARVALHINHO, 2012; SANTOS et al., 2015). Parece que uma aproximação do ser humano com a natureza está se revelando mais efetiva, e que as atividades de aventura na natureza estão se apresentando como estratégias significativas para a aproximação das pessoas com a educação ambiental (ROSA; CARVALHINHO, 2012).

Marinho e Inácio (2007) aprofundam-se nesta discussão e relatam que, com a popularização deste segmento, ocorre também uma disseminação das questões ambientais, 
abarcando temas que vão desde a proteção das espécies e ecossistemas até questões sociais, religiosas, étnicas e de qualidade de vida. Os autores consideram que as manifestações corporais proporcionadas por essas práticas oportunizam o reconhecimento de si mesmo e o do outro como parte do ambiente. Enfatizam, ainda, que a percepção quanto às questões ambientais e, principalmente, sua apropriação pelo indivíduo, está relacionada à reflexão sobre as necessidades humanas e seus valores socialmente construídos.

Aspectos emocionais também foram evidenciados pelos participantes. Alguns idosos se referiram à sua infância, às suas experiências passadas: "Eu fui criado aqui em Florianópolis, mas esta cidade antigamente era roça. Na época que eu fui criado, praticamente tinha mato para todos os lados, fazia anos que eu não andava no meio do mato" (RUI, 61) e "Eu vi uma série de remédios. Porque eu sou neta de índio, a minha mãe é filha de índio, índia biriva. Então desde criança vivi dentro do mato, eu conheci ervas e depois, claro, me distanciei" (CORA, 65); e sobre alguns sentimentos como amor pela natureza, sentimentos de tristeza pela degradação ambiental, o respeito à natureza, sobre o grupo ter respeitado o ambiente, bem como sobre a colaboração e o cuidado com a natureza. Alguns desses aspectos podem ser observados nas seguintes falas: "Acho que todo mundo respeitou, fez sua parte, participou, ninguém jogou nada, ninguém tirou uma folha. Todo mundo colaborou." (MARA, 74); e:

\footnotetext{
“A necessidade da preservação, da conservação. Aquele veio d'água nascendo ali quando a gente passou, aquilo ali é uma riqueza nos tempos de hoje. E quanto é preciso fazer para que se desperte a consciência das pessoas para cuidar, para manter, para não se apossar; porque aquilo ali é de todo mundo. [...]a mata me passou isso [...]" (CORA, 65).
}

Tais resultados evidenciam que os participantes percebem as questões ambientais não apenas ligadas à preservação e à conservação dos recursos naturais, mas também no que se refere aos valores e comportamentos individuais e coletivos e à qualidade de vida, ou seja, aos aspectos pessoais e sociais imbricados na questão ambiental, reafirmando que as atividades de aventura na natureza, no contexto do lazer, podem ser utilizadas no processo de educação ambiental, tanto no sentido de protagonismo do idoso como educador neste processo, quanto no sentido de desenvolvimento de valores e de aquisição de conhecimentos sobre o ambiente. A aproximação dos idosos, de forma sistematizada, às atividades de aventura na natureza pode lhes oferecer novas possibilidades de entendimento de si próprios e do ambiente. Além disso, tal aproximação pode contribuir para a perspectiva de desenvolvimento do comportamento pró-ambiental, fortalecendo a ideia de que o contato com a natureza torna-se fundamental para uma conscientização ecológica (CHAO et al., 2015).

Nesta mesma perspectiva, Corral-Verdugo (2000) preconiza a importância do trabalho interdisciplinar para auxiliar nas diversas dimensões da vida humana, a exemplo da social, a qual pode afetar o comportamento pró-ambiental, ou mesmo, este influenciar essas dimensões. Ainda, de acordo com este autor, os ambientes físico e sociocultural também 
interferem diretamente no comportamento dos indivíduos. Nesse sentido, estas dimensões se interligam e podem favorecer melhores resultados, quando exploradas conjuntamente, de modo a efetivar a importância de uma proposta interdisciplinar na vida humana e, respectivamente, em seu processo de formação, seja ele no contexto formal ou informal.

Marinho (2003) enfatiza, no contexto educacional, a necessidade de especialistas de várias áreas discutirem juntos melhores formas de interação entre o ser humano e a natureza. Nesse sentido, acredita-se ser importante que os organizadores das atividades de aventura na natureza sejam éticos, críticos e criativos no planejamento de suas atividades e das interações que ocorrerão entre os participantes e destes com o meio. Particularmente sobre a criatividade, é importante não a entender como sinônimo de improviso e vinculada às regras da "lógica", mas, sim, conforme salientam Bruhns e Marinho (2011), como diretamente relacionada à sensibilidade, no sentido de que esta pode ser convertida em criatividade ao ligar-se com uma atividade social significativa para o indivíduo. De acordo com Beedie (2003), o envolvimento com o ambiente durante as atividades de aventura na natureza pode se processar de maneira diferente entre os participantes e os instrutores, uma vez que estes últimos, geralmente, possuem contato intenso com o ambiente natural, ao passo que os participantes, na maioria dos casos, o fazem de maneira esporádica, cabendo aos instrutores instigarem a experimentação dos diversos sentidos dos participantes durante a vivência e a relação mais profunda com o entorno.

Cornell (1997) ressalta a necessidade do despertar dos diferentes sentidos durante as atividades na natureza, de modo a desenvolver a percepção e a sensibilidade nos praticantes. O autor destaca o papel do instrutor como primordial para o sucesso das vivências, sugerindo o trabalho em forma de aprendizado sequencial, no qual inicialmente deve-se despertar o entusiasmo do indivíduo para experimentar significativamente aquele momento; em seguida, concentrar a atenção do mesmo, de modo que ele possa observar os diferentes elementos ao redor; logo após, dirigir a experiência, explorando com mais detalhes os elementos ali presentes; e, por fim, compartilhar a inspiração, quando o instrutor pode contar suas experiências ou, ainda, abrir espaço para que os participantes partilhem suas histórias e percepções.

Durante a trilha oportunizada neste estudo existiram várias situações que possibilitaram aos idosos observarem as plantas, tocarem, comentarem sobre elas, ouvirem os sons da fauna, da água e do vento passando pela vegetação; existiram situações de auxílio mútuo em momentos de dificuldade na caminhada pela mata, que eram camufladas por condutas tímidas e um pouco receosas (como dar a mão, oferecer-se para segurar a bolsa, etc.). Essas experimentações corporais, proporcionadas por outros sentidos que não apenas a visão, como o tato, o olfato, a audição, segundo Marinho (2003), oportunizam uma relação mais íntima e intensa com o ambiente e com o outro, possibilitando novas significações do espaço e das relações estabelecidas.

Rosa e Carvalhinho (2012) ressaltam que é reconhecida a eficácia do contato com a natureza, por meio de atividades neste âmbito, na aquisição de maior consciência ambiental. Contudo, deve-se também reconhecer que para ocorrer a manutenção desta consciência torna-se necessário o contato contínuo com tais atividades. Neste presente estudo, pareceu 
que os idosos investigados, em geral, possuíam consciência ambiental previamente formada; porém, a vivência da trilha e do stand up paddle os auxiliaram a refletir sobre os aspectos sociais e ambientais a ela relacionados. Nesse sentido, a experimentação das atividades de aventura na natureza pela população idosa e a periodicidade de sua prática podem vir a tornar-se elemento de motivação para mais ações como a relatada neste estudo, contribuindo para a valorização dos aspectos socioambientais, a disseminação da sensibilização ambiental e/ou para o resgate do contato com o ambiente natural.

\section{CONSIDERAÇÕES FINAIS}

A partir dos resultados encontrados neste estudo, conclui-se que os idosos perceberam que a convivência, as conversas, as trocas de experiências e o apoio mútuo contribuíram para o estabelecimento de relações sociais que beneficiaram as relações interpessoais, durante a intervenção prática, seja entre os participantes ou com os instrutores e Profissionais de Educação Física. Diferentes aspectos foram mencionados quanto às reflexões sobre as questões ambientais: desde degradação à conservação; comportamentos, sentimentos e ações relacionados à natureza, sejam elas individuais ou coletivas; além de aspectos pontuais, como desmatamento, poluição, falta de água e lixo.

Esses resultados evidenciam que a participação de idosos nas atividades de aventura na natureza podem resultar em experiências sociais satisfatórias para os envolvidos, contribuindo para minimizar o isolamento social que pode ocorrer com idosos em algum momento de suas vidas, incluindo os idosos aqui investigados. Outro resultado importante a ser ressaltado é a possibilidade de reflexão sobre as questões ambientais proporcionada pelo contato com o ambiente, criando oportunidades para o questionamento sobre a realidade vivenciada. Nessa perspectiva, torna-se fundamental que o profissional atuante no mercado das atividades de aventura na natureza esteja preparado e devidamente capacitado para receber o público idoso, atendendo aos seus anseios e às suas necessidades, a fim de proporcionar uma vivência significativa, que promova o desenvolvimento social e pessoal, tendo em vista os benefícios dessas atividades como facilitadores da vivência de emoções, de descobertas, de superação de desafios e de relações interpessoais e com o meio natural.

Acredita-se que os resultados deste estudo possam fortalecer as discussões, ainda incipientes no cenário nacional, acerca dos aspectos socioambientais relacionados às atividades de aventura na natureza na perspectiva do segmento populacional de idosos. Além disso, espera-se que os dados encontrados nesta pesquisa possam contribuir com as interfaces entre a teoria e o contexto de prática de tais atividades, especialmente no âmbito do lazer.

Por se tratar de uma pesquisa desenvolvida com um grupo específico de idosos, incluindo poucos participantes, torna-se importante a realização de novas pesquisas sobre o assunto, avançando e superando as limitações deste trabalho. Sugere-se o desenvolvimento de estudos que busquem alcançar maior número de participantes e outras possibilidades de atividades de aventura na natureza, permitindo, desta forma, uma visão mais abrangente 
maio/2018

sobre as reflexões de idosos acerca dos aspectos socioambientais a partir da vivência de diferentes possibilidades envolvendo as atividades em questão.

\section{REFERÊNCIAS}

AZEVEDO, Sergio Luiz Gomes de; COCCHIARALE, Ney Felippe de Barros Rodrigues; COSTA, Vera Lucia de Menezes. A influência do risco-aventura no processo de coesão das diferentes comunidades do voo livre. Movimento, Porto Alegre, v. 16, n. 3, p. 259-278, jul./set. 2010.

BARDIN, Laurence. Análise de conteúdo. Tradução: Luis Antero Reto e Augusto Pinheiro. Ed. rev. actual. Lisboa: Edições 70, 2009.

BEEDIE, Paul. Mountain guiding and adventure tourism: reflections on the choreography of the experience. Leisure Studies, London, v. 22, n. 2, p. 147-167, 2003.

BETRÁN, Javier Olivera; BETRÁN, Alberto Olivera. Proposta pedagógica para as atividades físicas de aventura na natureza (AFAN) na educação física do ensino médio. In: MARINHO, Alcyane; BRUHNS, Heloisa Turini (Org.). Viagens, lazer e esporte. Barueri: Manole, 2006. p. 180-210.

BRASIL. Ministério da Educação. Base Nacional Comum Curricular. 2a . versão revista. Brasil, 2016. Disponível em: < http://basenacionalcomum.mec.gov.br/documentos/ bncc-2versao.revista.pdf $>$. Acesso em: 02 nov. 2016.

BROOKES, Andrew. A critique of neo-Hahnian outdoor education theory. Part one: Challenges to the concept of "character building". Journal of Adventure Education \& Outdoor Learning, UK, v. 3, n. 1, p. 49-62, 2003.

BRUHNS, Heloísa Turini; MARINHO, Alcyane. Criatividade: a exceção essencial. Revista Brasileira de Ciências e Movimento, Brasília, v. 19, n. 4, p. 97-107, abr./jun. 2011.

CAMILO, Christiane de Holanda. As possibilidades de atuação da educação física na educação de jovens e adultos para a relação intergeracional na educação em direitos humanos. Motrivivência, Florianópolis, v. 26, n. 43, p. 245-261, dez. 2014.

$\mathrm{CHAO}$, Cheng Hsin Nery et al. Atividades de aventura na natureza e desenvolvimento do comportamento pró-ambiental: análise comparativa entre idosos e condutores. Movimento, Porto Alegre, v. 21, n. 1, p. 169-180, jan./mar. de 2015.

CORNELL, Joseph. A alegria de aprender com a natureza: atividades ao ar livre para todas as idades. São Paulo: Companhia Melhoramentos, 1997.

CORRAL-VERDUGO, Victor. La definición del comportamiento proambiental. La Psicología Social en México, Guadalajara, v. 8, p. 466-472, 2000.

DIAS, Viviane Kawano. A participação de idosos em atividades de aventura na natureza no âmbito do lazer: valores e significados. 2006. 119 f. Dissertação (Mestrado em Ciências da Motricidade) - Universidade Estadual Paulista, Rio Claro, 2006.

DIMMOCK, Kay. Finding comfort in adventure: experiences of recreational SCUBA divers. Leisure Studies, Colchester, v. 28, n. 3, p. 279-295, jul. 2009.

GIL, Antonio Carlos. Métodos e técnicas da pesquisa social. 6. ed. São Paulo: Atlas, 2008. 
GILBERTSON, Ken; EWERT, Alan. Stability of motivations and risk attractiveness: the adventure recreation experience. Risk Management, Ljubljana, v. 17, p. 276-297, nov. 2015.

GOMES, Christianne Luce. Lazer: necessidade humana e dimensão da cultura. Revista Brasileira de Estudos do Lazer, Belo Horizonte, v. 1, n. 1, p. 3-20, jan./abr. 2014.

GOMES, Christianne Luce. Verbete Lazer - Concepções. In: GOMES, Christianne Luce (Org.). Dicionário crítico do lazer. Belo Horizonte: Autêntica, 2004. p.119-126.

MARCELLINO, Nelson Carvalho. Estudos do lazer: uma introdução. 5. ed. Campinas: Autores associados, 2012.

MARINHO, Alcyane. Lazer, aventura e risco: reflexões sobre atividades realizadas na natureza. Movimento, Porto Alegre, v. 14, n. 2, p. 181-206, maio/ago. 2008.

MARINHO, Alcyane. Da aceleração ao pânico de não fazer nada: corpos aventureiros como possibilidades de resistência. In: MARINHO, Alcyane; BRUHNS, Heloisa Turini (Org.). Turismo, lazer e natureza. Barueri: Manole, 2003. p. 1-28.

MARINHO, Alcyane; INACIO, Humberto Luís de Deus. Educação física, meio ambiente e aventura: um percurso por vias instigantes. Revista Brasileira de Ciências do Esporte, Campinas, v. 28, n. 3, p. 55-70, maio 2007.

MARINHO, Alcyane; SANTOS, Priscila Mari dos. Hábitos e percepções socioambientais na universidade: Educação Física e Fisioterapia em foco. Revista da Educação Física/ UEM, Maringá, v. 25, n. 3, p. 365-377, 3. trim. 2014.

MARINHO, Alcyane et al. Reflections about outdoor adventure sports and professional competencies of physical education students. Journal of Adventure Education and Outdoor Learning, Carlisle, v. 16, n. 1, p. 1-17, sep. 2016.

MAZO, Giovana Zarpellon; LOPES, Marize Amorim; BENEDETTI, Tânia Bertoldo. Atividade física e o idoso: concepção gerontológica. Porto Alegre: Sulina, 2009.

MINAYO, Maria Cecília de Souza. O desafio da pesquisa social. In: MINAYO, Maria Cecília de Souza; DELANDES, Suely Ferreira; GOMES, Romeu. Pesquisa social: teoria, método e criatividade. 32. ed. Petrópolis: Vozes, 2012. p. 9-29.

MINAYO, Maria Cecília de Souza. Trabalho de campo: contexto de observação, interação e descoberta. In: MINAYO, Maria Cecília de Souza; DELANDES, Suely Ferreira; GOMES, Romeu. Pesquisa social: teoria, método e criatividade. 31. ed. Petrópolis: Vozes, 2012. p. 61-77.

OLIVEIRA, Kamilla Paula Gandra de; NASCIMENTO, Alan Faber do. Revisando o lazer na terceira idade: uma proposta metodológica necessária. Licere, Belo Horizonte, v. 17, n. 3, p. 275-302, set. 2014.

PAIXÃO, Jairo Antônio et al. Risco e aventura no esporte na percepção do instrutor. Psicologia \& Sociedade, Belo Horizonte, v. 23, n. 2, p. 415-425, maio/ago. 2011. REIGOTA, Marcos. O que é educação ambiental. 2. ed. São Paulo: Brasiliense, 2009. RIZZOLLI, Darlan; SURDI, Aguinaldo César. Percepção dos idosos sobre grupos de terceira idade. Revista Brasileira de Geriatria e Gerontologia, Rio de Janeiro, v. 13, n. 2, p. 225-233, maio/ago. 2010. 
ROSA, Paulo Filipe; CARVALHINHO, Luís Alberto Dias. A educação ambiental e o desporto na natureza: uma reflexão crítica sobre os novos paradigmas da educação ambiental e o potencial do desporto como metodologia de ensino. Movimento, Porto Alegre, v. 18, n. 3, p. 259-280, jul./set. 2012.

SANTOS, Priscila Mari dos; MARINHO, Alcyane. Slackline e Educação Física: experiências do projeto de extensão "lazer e recreação". Licere, Belo Horizonte, v. 17, n. 4, p. 306-328, dez. 2014.

SANTOS, Priscila Mari dos et al. Formação profissional e percepção de competências de estudantes de educação física: uma reflexão a partir da disciplina de esportes de aventura e na natureza. Revista da Educação Física/UEM, Maringá, v. 26, n. 4, p. 529-540, 4. trim. 2015.

SORRENTINO, Marcos. Pessoas comprometidas com as transformações socioambientais - uma perspectiva latino-americana de educação ambiental. In: RAYMUNDO, Maria Henriqueta Adrade; BRIANEZI, Thaís; SORRENTINO, Marcos. (Orgs.). Como construir políticas públicas de educação ambiental para sociedades sustentáveis? São Carlos, SP: Diagrama Editorial, 2015. p.192-204.

SORRENTINO, Marcos. Desenvolvimento sustentável e participação: algumas reflexões em voz alta. In: LOUREIRO, Carlos Frederico Bernardo; LAYARGUES, Philippe Pomier; CASTRO, Ronaldo Souza (Org.). Educação ambiental: repensando o espaço da cidadania. São Paulo: Cortez, 2002. p. 15-21.

TAHARA, Alexander Klein; CARNICELLI FILHO, Sandro. Atividades físicas de aventura na natureza (AFAN) e academias de ginástica: motivos de aderência e benefícios advindos da prática. Movimento, Porto Alegre, v. 15, n. 3, p. 187-208, jul./set. 2009.

WHEATON, Belinda. Surfing through the life-course: silver surfers' negotiation of ageing. Annals of Leisure Research, v. 13, n. 1, p. 1-21, abr. 2016. Disponível em: < http:// dx.doi.org/10.1080/11745398.2016.1167610>. Acesso em: 10 nov. 2016.

Recebido em: Fevereiro/2017

Aprovado em: Junho/2017 